\title{
Sigmoidoscopy in minor lower gastrointestinal bleeding
}

\author{
E Balkan, İ Kırıştıŏlu, A Gürpınar, İ Özel, K Sınmaz, H Doğruyol
}

\begin{abstract}
The role of sigmoidoscopic examination in the diagnosis, evaluation, and treatment of minor lower gastrointestinal bleeding was investigated. A hundred patients with minor rectal bleeding were examined by rigid sigmoidoscopy under general anaesthesia between January 1989 and July 1996.

Patients who had bleeding secondary to infections, anal fissure, or haemorrhoids were excluded from study. Patients were reviewed retrospectively according to their diagnosis and endoscopic and histopathological findings. Twenty nine of these patients were girls and 71 boys; their ages ranged between 8 month and 14 years (mean 7.2 years). Endoscopic pathological findings were established in 60 patients; 32 had rectal polyps, 16 non-specific proctitis, four solitary rectal ulcers, three internal haemorrhoids, two ulcerative colitis, two Hirschsprung's enterocolitis, and one haemangioma.

It is concluded that sigmoidoscopic examination should be performed for the diagnosis, prognosis, and choice of treatment in patients with minor rectal bleeding and the diagnosis should be confirmed histopathologically.

(Arch Dis Child 1998;78:267-268)
\end{abstract}

Keywords: gastrointestinal haemorrhage; rectal bleeding; sigmoidoscopy

Minor or chronic gastrointestinal bleeding, defined as haemorrhage that does not affect haemodynamic status, is less than $20 \%$ of total blood volume and often results in chronic anaemia. ${ }^{1}$ Endoscopic and histopathological examinations are imperative in diagnosis. Sigmoidoscopy is widely used for this purpose.

In our study, we investigated the role of sigmoidoscopic examination in the diagnosis, evaluation, and treatment of minor lower gastrointestinal bleeding.

\section{Subjects and methods}

Between January 1989 and July 1996, 119 sigmoidoscopic examinations were carried out in 100 patients with a history of rectal bleeding. All sigmoidoscopic examinations were done in the lateral Sims position, under general anaesthesia and using a rigid sigmoidoscope. Patients with anal fissure, haemorrhoids, or rectal bleeding caused by infection were excluded from the study. The endoscopic and histopathological findings of the cases were evaluated retrospectively.

\section{Results}

Seventy one of the cases were boys and 29 girls. Age distribution ranged between 8 months and 14 years. The male:female ratio was $2.2: 1$. In 60 patients rectal polyps, non-specific proctitis, solitary rectal ulcers, internal haemorrhoids, Hirschsprung's enterocolitis, and haemangioma were observed on sigmoidoscopic examination (table 1). Of these, the most common were rectal polyps (32 patients, 53.3\%). Sigmoidoscopic examination was normal in 40 patients. In the follow up period, none of them had developed de novo rectal bleeding.

Rectal polyps were found 2.2 times as often in boys than girls and the peak age was 6 (fig 1). There were multiple polyps in two patients. Diagnosis was made on rectal digital examination in $66 \%$ of the cases $(n=21)$. The digital examination false positive ratio was $25 \%$ and false negative ratio was $12 \%$. Distal rectal polyps were exteriorised by clamp from the anus and removed. Others were treated endoscopically. Histopathological diagnosis was juvenile in $29(90.6 \%)$, hyperplastic in two $(6.3 \%)$, and squamous metaplasia in one case (3.1\%).

On endoscopic examination, the presence of hyperaemia, oedema, or a granular appearance of the rectal mucosa were accepted as representing proctitis.

The diagnoses of non-specific proctitis were confirmed histopathologically in 12 of 16 of the suspected proctitis cases. Four of them showed normal appearance on histopathological examinations.

The presence of ulcers, thickening, or a polypoid appearance of the rectal mucosa was defined as solitary rectal ulcer. We encountered four such cases at sigmoidoscopic examination.

Table 1 Diagnosis in 60 patients

\begin{tabular}{lc}
\hline Primary diagnosis & No (\%) of patients \\
\hline Rectal polyps & $32(53.3)$ \\
Non-specific proctitis & $16(26.7)$ \\
Solitary rectal ulcers & $4(6.7)$ \\
Internal haemorrhoids & $3(5.0)$ \\
Hirschsprung's enterocolitis & $2(3.3)$ \\
Haemangioma & $1(1.6)$ \\
\hline
\end{tabular}

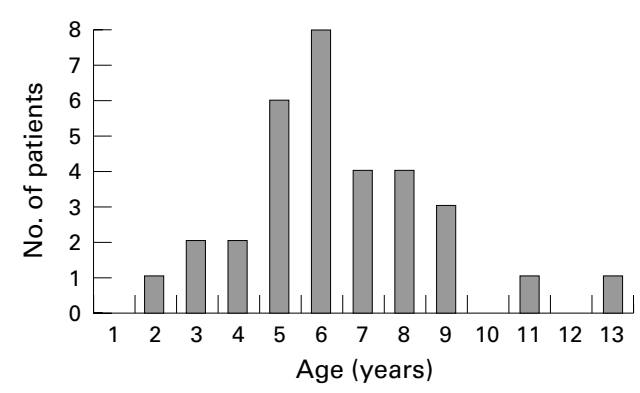

Figure 1 Age distribution of patients with rectal polyps. 
On histopathological examination, there were both ulceration and granulation tissues on the ulcer bed.

Repeated endoscopies were performed in eight patients. These patients included solitary rectal ulcer $(n=4)$, ulcerative colitis $(n=2)$, and non-specific proctitis $(n=2)$. Two patients with ulcerative colitis were found to be in remission on repeated endoscopy and histopathology. In subsequent endoscopic examination of two patients with non-specific proctitis, lesions were found to be healed in one, although there was repeated bleeding caused by a polyp. In the other patient, non-specific proctitis persisted. Complete healing was observed in three of four solitary rectal ulcer cases. Moderate healing was seen in one.

\section{Discussion}

Polyps and inflammatory intestinal diseases are frequently seen in children. The first approach to a patient with rectal bleeding should be inspection and digital examination. Anal fissures, rectal polyps, and haemorrhoids can be easily diagnosed. The second step should be examination of faeces. In a study performed in Turkey, the incidence of protozoal infection was $33.6 \%$ in 1089 patients with rectal bleeding. ${ }^{2}$ As a third step, examination and endoscopy should be performed under general anaesthesia. We took all three steps in all cases. Some lesions that could not be detected at an earlier stage were diagnosed under general anaesthesia. This may be due to patients' age, non-cooperation, insufficient clearance of rectum, proximal location of lesion, or lack of experience of the surgeon.

In other studies, diagnoses of rectal polyp by rectal digital examination has been reported in $60-75 \% .{ }^{13}$ It was determined in $66 \%$ of our cases. Rectal bleeding is often caused by gastrointestinal benign lesions in children, of which $80 \%$ are juvenile polyps. ${ }^{4}$ In our series, rectal polyps were the most common discovered cause $(53.3 \%)$ of rectal bleeding. The age at which polyps were mostly seen has been reported to be from 3 to 7 years. ${ }^{156}$ The mean age of our patients was 6 (range 2 to 11) years. Rectal bleeding did not recur after endoscopic or open polypectomy in any of the children.

Solitary rectal ulcer syndrome has been reported rarely in children. ${ }^{78}$ The diagnosis depends on endoscopic appearance and histopathological confirmation. ${ }^{8}$ We diagnosed four solitary rectal ulcers with rectal bleeding. The difficulty in diagnosis is generally due to differences in macroscopic appearance. Although $50 \%$ of cases are seen as ulcers, mucosal thickening and polypoid lesions can also be observed. ${ }^{9-11}$ Polypoid lesions are frequently seen in children. ${ }^{72}$ In all four of our cases ulcers were present and two had pseudopolyp formation. Fibrosis in the lamina propria is the most important criterion in diagnosing solitary rectal ulcer syndrome with or without the presence of an ulcer. Fibrosis is not seen in inflammatory intestinal diseases that have similar clinical findings. ${ }^{13} 14$

\section{Key messages}

- The first approach to patients with rectal bleeding should be inspection and rectal digital examination

- The second step should be examination of faeces

- Sigmoidoscopic examination should be performed for diagnosis, prognostic evaluation, and choice of treatment in patients with persistent rectal bleeding

- The diagnosis should be confirmed by histopathology

In other studies non-specific proctitis is often not clearly defined and is considered a transient condition. Although it is accepted as a variant of diffuse ulcerative colitis, clinical manifestations and prognosis are extremely different from ulcerative colitis. ${ }^{15}$ Lesions are often confined to the rectum, although sometimes they can extend to the sigmoid colon. ${ }^{16}$ Diagnosis was confirmed by histopathologically in 12 of our 16 cases diagnosed as non-specific proctitis on endoscopic examination. On clinical follow up, rectal bleeding reoccurred in only two cases.

We conclude that sigmoidoscopic examination should be performed for diagnosis, prognostic evaluation, and help in choosing treatment in patients with persistent rectal bleeding, and the diagnosis should be confirmed histopathologically.

1 Raffensperger JG, Luck SR. Gastrointestinal bleeding in children. Surg Clin North Am 1976; 56:413-24.

2 Başaklar AC, Atayurt HF, Kansu E. Cocuklarda alt sindirim sistemi kanamaları. Çocuk Hastalıklar Dergisi 1988;7:11-6.

3 Stevenson RJ. Gastrointestinal bleeding in children. Surg Clin North Am 1985;65:1455-80.

4 Soper RT. Gastrointestinal neoplasms. In: Ashcraft KW, Soper RT. Gastrointestinal neoplasms. In: Ashcraft KW,
Holder TM eds. Pediatric surgery. Philadelphia: WB SaunHolder TM eds. Pediatr
ders, 1993: 453-66.

5 Rowe Ml. Polypoid diseases of the gastrointestinal tract. In: Rowe MI, ed. Essentials of pediatric surgery. St Louis, Missouri: Mosby, 1995: 561-9.

6 Perisic VN. Colorectal polyps:an important cause of rectal bleeding. Arch Dis Child 1987;62:188-203.

7 Sondheimer JM, Slagle TA, Bryke CR, et al. Solitary rectal ulcer syndrome in a teenaged boy. $\mathcal{F}$ Pediatr Gastroenterol Nutr 1985;4:835-8.

8 Eigenmann PA, Le Coultre C, Cox J, et al. Solitary rectal ulcer: an unusual cause of rectal bleeding in children. Eur $\mathcal{F}$ Pediatr 1992;151:658-60.

9 Figueroa-Colon RE, Jounoszai MK, Mitros FA. Solitary rectal ulcer syndrome of the rectum in children. F Pediatr Gastroenterol Nutr 1989;8:408.

10 Alberti-Flor JJ, Halter S, Dunn GD. Solitary rectal ulcer: a cause of massive lower gastrointestinal bleeding. Gastroin-

test Endosc 1985;1:53-4.
11 Kuijpers JHC, Baeten C, Shreven RH, et al. Solitary rectal ulcer syndrome: result of functional defecation disorders? Dig Surg 1988;5:43-6.

12 Levine DS. "Solitary" rectal ulcer syndrome: are "solitary" rectal ulcer syndrome and "localized" colitis cystica profunda analogous syndromes caused by rectal prolapse? Gastroenterology 1987;92:243-53.

13 Gündoğdu ZH, Altın MA, Aksoy F, et al. Solitary rectal ulcer in a 12 year old girl: an usual cause of rectal bleeding in childhood. Pediatr Surg Int 1994;9:131-2.

14 Tjandra JJ, Fazio VW, Petras RE, et al. Clinical and pathologic factors associated with delayed diagnosis in solitary rectal ulcer syndrome. Dis Colon Rectum 1993;36:14653.

15 Earnest DL, Sleisenger MH. Other diseases of the colon and rectum. In: Sleisenger MH, Fordtran JS, eds. Gastrointestinal disease. Philadelphia: WB Saunders, 1975: 1534-5.

16 Jayanthi V, Chuah SY, Probert CS, et al. Proctitis and proctosigmoiditis: a need to identify the extent of disease in proctosigmoiditis: a need to identify the extent of
epidemiological surveys. Digestion 1993;54:61-4. 